\title{
Wrist and Forehead Temperature Measurement as Screening Methods During the COVID-19 Pandemic
}

\author{
Imtinan Malawi, Thamer Alsohabani, Mashael Aleidan, Nawa Al shahrani, Adel Karairi, Bandr Mzahim, and \\ Sharafaldeen Bin Nafisah
}

\begin{abstract}
Background: Temperature screening checkpoints have become widely distributed during the COVID-19 pandemic, using various contactless methods of temperature measurement, including wrist and forehead measurement.

Aim: In this study we aim to investigate the sensitivity and specificity of these two temperature measurement methods - wrist and forehead - compared with the standards of sublingual or axillary measurement. We also aim to investigate the influence of age, gender, device brand and diurnal effect on the temperature reading.

Methods: Participants were randomly assigned to one of two groups, each group using a different temperature measurement device. All participants had their forehead and wrist temperature measured, and this was compared to their axillary or sublingual readings.

Results: The area under the curve for wrist measurement was $0.49(95 \%$ CI 0.34 and 0.64$), p>0.05$, with a sensitivity of $46.2 \%$ and specificity of $53.3 \%$, while the area under the curve for forehead measurement was $0.70(95 \%$ CI $0.51,0.89), \quad p<0.05$, with a sensitivity of $23.1 \%$ and specificity of $76.9 \%$, PPV $1.59 \%$ and NPV 97.7\%.

Conclusion : Wrist and forehead temperature measurement is not accurate in detecting fever during the ongoing COVID19 pandemic. Although forehead measurement is also not an ideal method, it nevertheless appears more consistent than wrist measurement.
\end{abstract}

Index Terms-Wrist Temperature, Forehead Temperature, Temperature screenings

\section{INTRODUCTION}

From mercury-based to contactless infrared measurement, the advance in thermometer devices has significantly transformed fever detection. Contactless measurement is appealingly convenient given the increased community use of fever detection devices during the COVID-19 era. However, detection methods vary across different settings, where various improvised methods are used. For instance, the use of an infrared thermometer on the wrist appears to be widely accepted, despite its design for use on the forehead. Examination of the efficacy of these improvised methods reveals mixed results. In

Imtinan Malawi, Thamer Alsohabani, Adel Karairi, Bandr Mzahim, Sharafaldeen Bin Nafisah are with Emergency Department, King Fahd Medical City, Saudi Arabia, e-mail: Imtenanma@gmail.com, e-mail: Thamersoh@windowslive.com, e-mail: akarairi@kfmc.med.sa, e-mail: bmzahim@kfmc.med.sa, e-mail: sbinnafisah@kfmc.med.sa (Corresponding author: Imtinan Malawi)

Mashael Aleidan is with Majmma University, Saudi Arabia, e-mail: mashael.aleidan@gmail.com

Nawa Al shahrani is with King Khalid University, Saudi Arabia, e-mail: Nawa202059@hotmail.com one study, wrist measurement was unreliable when compared with tympanic membrane measurement [1]; in another, it exhibited higher sensitivity [2].

Forehead measurement, on the other hand, has been criticised for its inaccuracy, and it has been suggested that any reading above $35.6^{\circ} \mathrm{C}$ should be noted as fever [3], [4]. Such inaccuracy is attributed to the device brand and its variable sensitivity compared with other methods [4], [5]. Therefore, we aim in this study to investigate the sensitivity and specificity of these two temperature measurement methods - wrist and forehead - when compared with the sublingual or axillary standard methods. We also aim to investigate the influence of age, gender, device brand and diurnal effect on the temperature reading.

\section{METHOD}

We included all patients - adults and paediatrics - presenting to the triage area of the emergency department at King Fahd Medical City, Saudi Arabia, between 6 December 2020 and 17 February 2021. The exclusion criteria were: level 1 classification on the Canadian Triage and Acuity Scale (CTAS), as these patients bypass the vital sign assessment in the triage area. Participation was voluntary, with a $100 \%$ participation rate. Data were collected in an online form and included the time of measurement, patients' age and gender, device brand, the temperature reading of the wrist and forehead, and either the axillary or sublingual reading. Two devices were chosen, based on their availability on the online market and their use at Saudi Arabia's various checkpoints. The first device is the handheld Vibeey HW-F7 Digital Non-contact Forehead Infrared Thermometer (Long Hua Xin Qu Shenzhen Guangdong 518109, China), referred to herein as device I. Device II was the handheld Beurer FT 65 Multi-functional Thermometer (Soeflinger Strasse 218 Ulm, 89077 Germany). The device used for sublingual and axillary measurement was the PHILIPS Mindray VS-800, Ver.1 (China).

We estimated a sample size of 300 patients for an accurate effect size [6]. The standard method of temperature measurement was sublingual for adult patients and axillary for paediatrics; however, crossover of the standard methods between the age groups was allowed.

Given the variation in the literature on what constitutes normal body temperature, we used a reference temperature value ranging from $36.0^{\circ} \mathrm{C}-37.7^{\circ} \mathrm{C}$ [7], [8]. This range 
considers the different measurement methods, the time of day and the weather. The study was approved by the Ethics Committee, and we complied with the STROBE guidelines when reporting this study [9].

\section{RESULTS}

Demographics: The total number of participants in our analysis was 627 . The participants were randomly divided into two groups, each of which was assigned one of the devices. Handheld Device I was used on 302 patients, and Device II on 325. The participants' mean age was 35.7 years $(\mathrm{SD}=21.1)$. The various demographics, the devices and the measurement methods are illustrated in Table 1.

Baseline values: The mean temperature using the standard method was $36.6^{\circ} \mathrm{C}(\mathrm{SD}=0.41)$, using the wrist method was $35.6^{\circ} \mathrm{C}(\mathrm{SD}=1.30)$, while the forehead method revealed a mean of $36.1^{\circ} \mathrm{C}(\mathrm{SD}=0.80)$.

Wrist temperature measurement: The difference between the wrist temperature and the standard was $0.99^{\circ} \mathrm{C}(\mathrm{SD}=1.35)$, with a range from $-1.1^{\circ} \mathrm{C}$ to a maximum of $8.9^{\circ} \mathrm{C}$. There was no correlation between wrist temperature and standard temperature; $\mathrm{r}=0.04, \mathrm{n}=627, \mathrm{p}>0.05$. The wrist temperature did not reveal a significant regression equation; $\mathrm{p}>0.05$.

The sensitivity of the wrist temperature measurement was $46.2 \%$, and the specificity was $53.3 \%$. The PPV was $2.04 \%$ and NPV was $97.9 \%$, with an overall accuracy of $53 \%$. The area under the curve (AUC) was 0.49 (95\% CI 0.34 and 0.64 ), $\mathrm{p}>0.05$; this is illustrated in Figure 1.

Forehead temperature measurement: The difference between the forehead temperature and the standard was $0.49^{\circ} \mathrm{C}$ $(\mathrm{SD}=0.83)$, ranging from $-1.90^{\circ} \mathrm{C}$ to a maximum of $3.30^{\circ} \mathrm{C}$. There was an acceptable correlation with the standard method; $\mathrm{r}=0.41, \mathrm{n}=627, \mathrm{p}<0.05$. Linear regression was conducted to predict the standard temperature based on forehead temperature, and a significant regression equation was found: $[F(2,624)=10.50, p<0.05]$ with an $R^{2}$ of 0.03 .

The AUC for forehead temperature measurement was 0.7, which indicates that forehead temperature measurement is better than chance alone; area $=0.70,(95 \% \mathrm{Cl} 0.51,0.89)$, $\mathrm{p}<0.05$. This is illustrated in Figure 2. The sensitivity of the forehead method is $23.1 \%$ and the specificity is $76.9 \%$, with a PPV of $1.59 \%$ and NPV of $97.7 \%$. Table 2. illustrates the coordinates of the curve.

Variables affecting measurement:

-Age effect: wrist temperature revealed a negative correlation with age, $\mathrm{r}=-0.83, \mathrm{n}=627, \mathrm{p}<0.05$. A significant regression equation was found: $[\mathrm{F}(1,625)=1.85, \mathrm{p}<0.05]$ with an $\mathrm{R}^{2}$ of 0.003 . However, forehead temperature had no correlation with the participants' age $\mathrm{r}=-0.29, \mathrm{n}=627, \mathrm{p}>0.05$.

-Gender effect: Gender did not influence the wrist or forehead temperature and the standard temperature, $p>0.05$.

-Device brand: We noted a significant variation between Device I and Device II in wrist and forehead temperatures. The difference between wrist and standard temperature using Device II was greater than when using Device I: $(\mathrm{M}=1.58$, $\mathrm{SD}=1.49)$ vs $(\mathrm{M}=0.36, \mathrm{SD}=0.77) ; \mathrm{t}(494.45)=-12.91, \mathrm{p}<0.05$. Similarly, Device II revealed a higher forehead mean $(\mathrm{M}=0.80$,
$\mathrm{SD}=0.99)$ than Device $\mathrm{I}(\mathrm{M}=0.16, \mathrm{SD}=0.41) ; \mathrm{t}(440.20)=-$ $10.86, \mathrm{p}<0.05$.

- Diurnal temperature variation: An independent sample ttest was used to investigate a possible diurnal effect on temperature readings using the wrist method. We noted a significant difference, whereby temperatures measured during the afternoon and/or evening were lower $(\mathrm{M}=35.52, \mathrm{SD}=1.81)$ than those measured in the morning hours $(\mathrm{M}=35.98)$; $\mathrm{t}(593.7)=-$ $4.05, \mathrm{p}<0.05$.

The possibility of a diurnal effect on forehead temperature measurement was also investigated using an independent sample t-test. We noted a significant difference, whereby temperatures were lower in the afternoon/evening hours $(\mathrm{M}=36.05$, $\mathrm{SD}=0.84)$ than in the morning hours $(\mathrm{M}=36.29, \mathrm{SD}=0.67)$; $\mathrm{t}(453.5)=-3.69, \mathrm{p}<0.05$.

The standard method did not reveal any significant difference in temperature between afternoon/evening $(\mathrm{M}=36.62$, $\mathrm{SD}=0.43)$ and morning $(\mathrm{M}=36.59, \mathrm{SD}=0.39) ; \mathrm{t}(626)=0.93$, $\mathrm{p}>0.05$.

\section{DISCUSSION}

To the time of writing, this is the first analysis of the sensitivity of wrist and forehead temperature screening methods using such comparison. We found that the wrist method is less accurate, less sensitive, and less specific when compared with the sublingual and axillary methods. The AUC for wrist temperature is less than 0.5 ; this suggests that the wrist method of temperature measurement is no better than chance alone. This was noted for both adult and paediatric populations. Even where the thermometer reveals a fever, the probability of the individual having COVID-19 is very low, given its low PPV. We also noted a high NPV, indicating that when the thermometer reveals a normal temperature, the probability that the individual does not have a fever is very high. This is falsely assuring, given its lower sensitivity and the influence of age, time of the day, and device brand. It might be argued that a lower temperature should be set as a threshold; nonetheless, many factors influence its measurement and we discourage its use.

The forehead method appeared superior to the wrist method, correlating with both the sublingual and the axillary measurements, with an acceptable AUC. This suggests that the forehead temperature reading can predict the actual temperature, yet it has a lower sensitivity than the wrist method. Like the wrist method, its accuracy is influenced by the device brand and time of day, but unlike the wrist method, not by the patient's age. Furthermore, the higher the temperature reading, the lower the sensitivity becomes. Such findings are aligned with those of a previous study [4].

\section{CONCLUSION}

It is prudent to assert that both methods are far from ideal. The higher sensitivity recorded using the wrist method, as described in one study, is based on the use of only one device brand [10]. We investigated this confounder and noted that the brand of device influences the temperature reading. The 


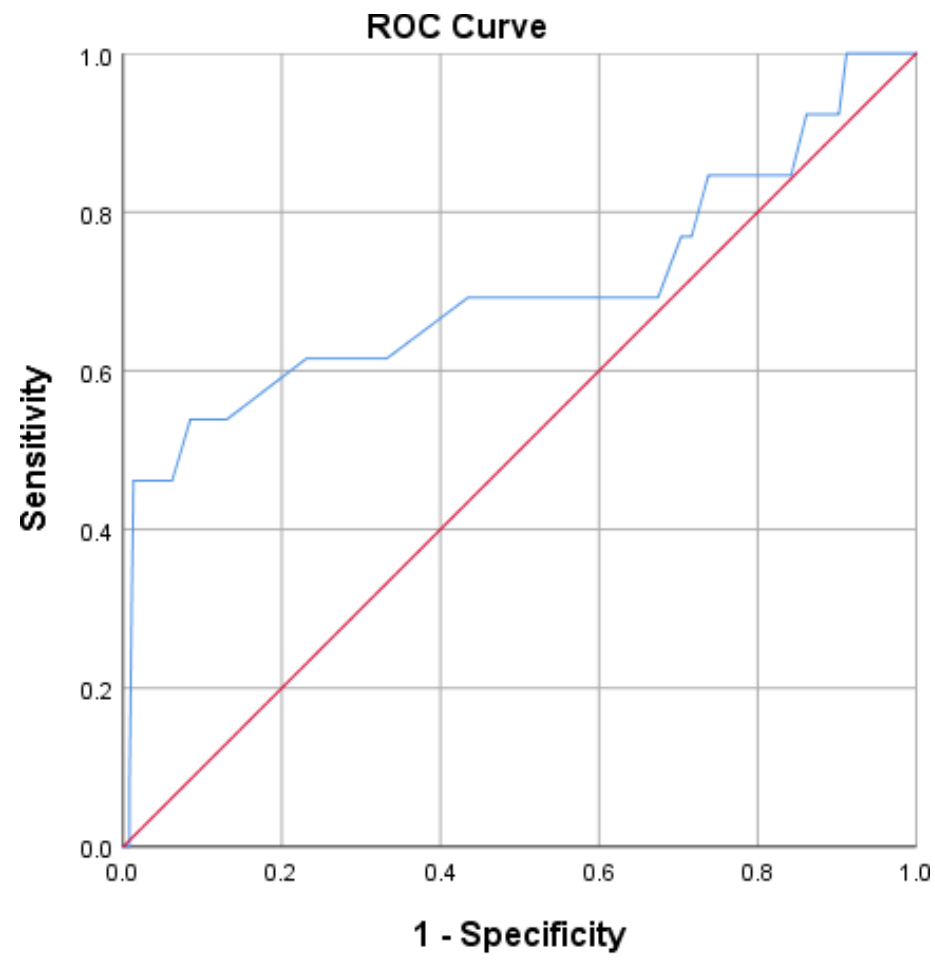

Diagonal segments are produced by ties.

Fig. 1. The receiver operating characteristic (ROC) curve of the wrist measurement method for both adults and paediatrics

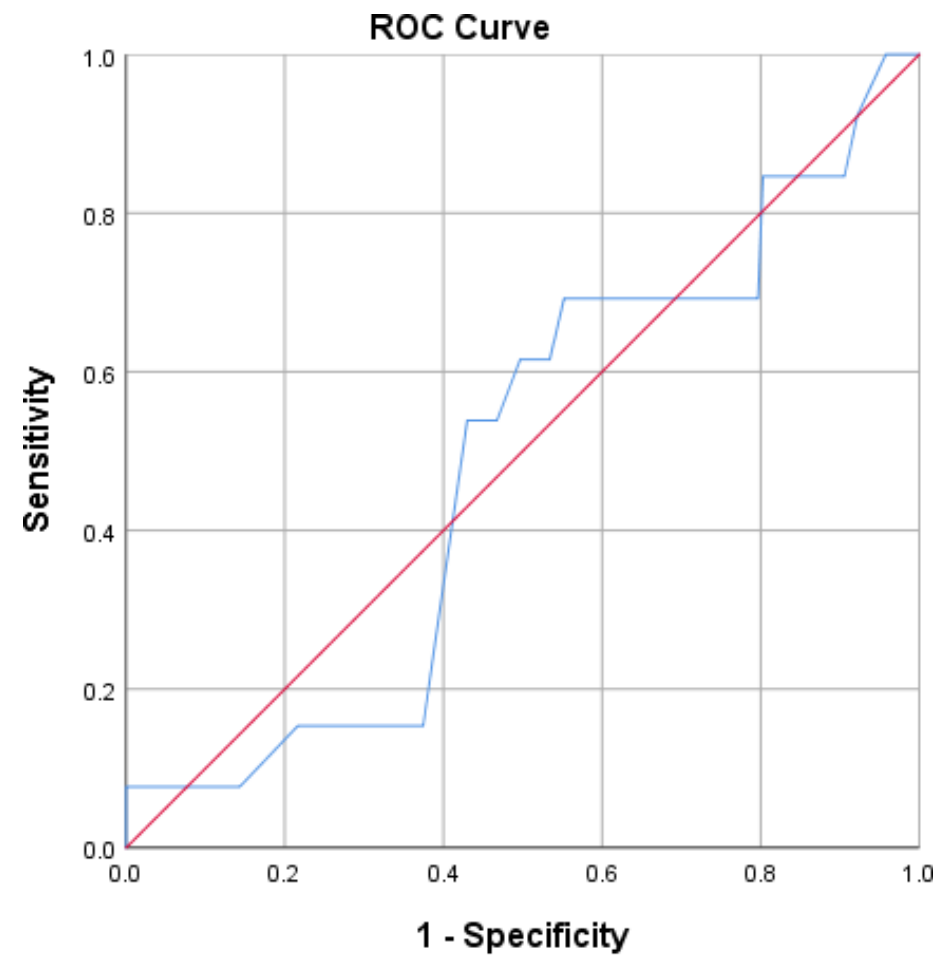

Diagonal segments are produced by ties.

Fig. 2. The ROC curve of the forehead measurement method when compared with the standard method for both adults and paediatrics 
device bias and the influence of the time of day was noted in our study and in several others [11], [12], [13].

It should be emphasised that reliance on these methods does not facilitate early detection or containment. Furthermore, with the widespread mandatory use of masks and the asymptomatic features of some COVID-19 cases [14], we see no value in using inaccurate tools. Likewise, the wide variation between devices discourages any attempt to set a lower temperature threshold for screening. Further studies are advised, to compare whole-body temperature devices and to compare device sensitivity and specificity.

\section{REFERENCES}

[1] "Infrared Sensors on Core Body Temperature Monitoring by Comparing Measurement Sites," Sensors, vol. 20, pp. 2885-2885, 2020.

[2] [Online]. Available: https://www.medrxiv.org/content/10.1101/2020.03. $02.20030148 \mathrm{v} 1$

[3] A. Abdi, S. Asadian, A. Khatony, G. R. Moradi, and M. Rezaei, "Accuracy and precision of four common peripheral temperature measurement methods in intensive care patients," in Medical Devices: Evidence and Research, vol. Volume 9. Informa UK Limited, 2016, pp. 301-308. [Online]. Available: 10.2147/mder.s109904;https: //dx.doi.org/10.2147/mder.s109904

[4] D. K. Ng, C. H. Chan, E. Y. Chan, K. L. Kwok, P. Y. Chow, W. F. Lau, and J. C. Ho, "A brief report on the normal range of forehead temperature as determined by a non-contact, handheld, infrared thermometer," Am J Infect Control, vol. 33, no. 4, pp. 7115 295-7 115 295, 2005.

[5] J. Teller, M. Ragazzi, G. D. Simonetti, and S. A. G. Lava, "Accuracy of tympanic and forehead thermometers in private paediatric practice," Acta Paediatrica, vol. 103, no. 2, pp. e80-e83, 2014. [Online]. Available: 10.1111/apa.12464;https://dx.doi.org/10.1111/apa.12464

[6] M. A. Bujang, "Requirements for Minimum Sample Size for Sensitivity and Specificity Analysis," JOURNAL OF CLINICAL AND DIAGNOSTIC RESEARCH, vol. 10, pp. 106, 2016. [Online]. Available: 10.7860/jcdr/2016/18129.8744;https: //dx.doi.org/10.7860/jcdr/2016/18129.8744

[7] P. A. Mackowiak and G. Worden, "Carl Reinhold August Wunderlich and the Evolution of Clinical Thermometry," Clinical Infectious Diseases, vol. 18, no. 3, pp. 458-458, 1994. [Online]. Available: 10.1093/clinids/18.3.458;https://dx.doi.org/10.1093/clinids/18.3.458

[8] I. I. Geneva, B. Cuzzo, T. Fazili, and W. Javaid, "Normal Body Temperature: A Systematic Review," Open Forum Infectious Diseases, vol. 6, no. 4, pp. 32-32, 2019. [Online]. Available: 10.1093/ofid/ofz032;https://dx.doi.org/10.1093/ofid/ofz032

[9] E. von Elm, D. G. Altman, M. Egger, S. J. Pocock, P. C. Gøtzsche, and J. P. Vandenbroucke, "The Strengthening the Reporting of Observational Studies in Epidemiology (STROBE) Statement," Epidemiology, vol. 18, no. 6, pp. 800-804, 2007. [Online]. Available: 10.1097/ede.0b013e3181577654;https: //dx.doi.org/10.1097/ede.0b013e3181577654

[10] C. G, J. Xie, D. G, P. Zheng, L. U. H. X, Hl, C. X. X. L, and

C. X, "Validity of the Use of Wrist and Forehead Temperatures in Screening the General Population for COVID-19: A Prospective RealWorld Study," Iran J Public Health, vol. 49, pp. 57-66.

[11] D. J. Casa, S. M. Becker, M. S. Ganio, C. M. Brown, S. W. Yeargin, M. W. Roti, J. Siegler, J. A. Blowers, N. R. Glaviano, R. A. Huggins, L. E. Armstrong, and C. M. Maresh, "Validity of devices that assess body temperature during outdoor exercise in the heat," $J$ Athl Train, vol. 42, no. 3, pp. 333-375, 2007.

[12] U. Erenberk, E. Torun, E. Ozkaya, S. Uzuner, A. D. Demir, and R. Dundaroz, "Skin temperature measurement using an infrared thermometer on patients who have been exposed to cold," Pediatrics International, vol. 55, no. 6, pp. 767-770, 2013. [Online]. Available: 10.1111/ped.12188; https://dx.doi.org/10.1111/ped.12188

[13] H. Y. Chen, A. Chen, and C. Chen, pp. 2885-2885, 2020

[14] D. Han, R. Li, Y. Han, R. Zhang, and J. Li, "COVID-19: Insight into the asymptomatic SARS-COV-2 infection and transmission," International Journal of Biological Sciences, vol. 16, no. 15, pp. 2803-2811, 2020. [Online]. Available: 10.7150/ijbs.48991;https: //dx.doi.org/10.7150/ijbs.48991 
TABLE I

ILLUSTRATES THE DEMOGRAPHICS, THE DEVICES, AND THE METHODS OF MEASUREMENT

\begin{tabular}{ll}
\hline VARIABLE(S) & PercentAGE (n) \\
Age groups & $16.3(102)$ \\
Paediatric patients & $83.7(524)$ \\
Adult patients & \\
Gender & $49(307)$ \\
Male & $51(320)$ \\
Female & \\
Devices & $82.9(502)$ \\
Sublingual Standard Method & $17.1(107)$ \\
Standard Axillary Method & $48.2(302)$ \\
Handheld device no. I & $51.8(325)$ \\
Handheld device no. II & \\
Handheld device no. I & $6.9(43)$ \\
Paediatric & $41.2(258)$ \\
Adult & \\
Handheld device no. II & $9.4(59)$ \\
Paediatric & $42.5(266)$ \\
Adult & \\
Standard Method-Sublingual & \\
Paediatric & $2.4(15)$ \\
Adult & $80.5(504)$ \\
Standard Method-Axillary & \\
Paediatric & $13.9(87)$ \\
Adult & $3.2(20)$ \\
\hline &
\end{tabular}

TABLE II

ILLUSTRATES THE COORDINATES OF THE CURVE FOR THE FOREHEAD TEMPERATURE METHOD.

\begin{tabular}{|c|c|c|}
\hline Positive if Greater Than or Equal To & Sensitivity & 1 - Specificity \\
\hline $33.0{ }^{\circ} \mathrm{C}$ & 1 & 1 \\
\hline $34.1{ }^{\circ} \mathrm{C}$ & 1 & 0.989 \\
\hline $34.2{ }^{\circ} \mathrm{C}$ & 1 & 0.985 \\
\hline $34.3{ }^{\circ} \mathrm{C}$ & 1 & 0.969 \\
\hline $34.4^{\circ} \mathrm{C}$ & 1 & 0.959 \\
\hline $34.5{ }^{\circ} \mathrm{C}$ & 1 & 0.940 \\
\hline $34.6{ }^{\circ} \mathrm{C}$ & 1 & 0.920 \\
\hline $34.7^{\circ} \mathrm{C}$ & 1 & 0.912 \\
\hline $34.8{ }^{\circ} \mathrm{C}$ & 0.923 & 0.902 \\
\hline $34.9{ }^{\circ} \mathrm{C}$ & 0.923 & 0.899 \\
\hline $34.9{ }^{\circ} \mathrm{C}$ & 0.923 & 0.886 \\
\hline $35.1{ }^{\circ} \mathrm{C}$ & 0.923 & 0.868 \\
\hline $35.2{ }^{\circ} \mathrm{C}$ & 0.923 & 0.862 \\
\hline $35.3^{\circ} \mathrm{C}$ & 0.846 & 0.842 \\
\hline $35.4^{\circ} \mathrm{C}$ & 0.846 & 0.811 \\
\hline $35.5^{\circ} \mathrm{C}$ & 0.846 & 0.796 \\
\hline $35.6{ }^{\circ} \mathrm{C}$ & 0.846 & 0.772 \\
\hline $35.7^{\circ} \mathrm{C}$ & 0.846 & 0.756 \\
\hline $35.8{ }^{\circ} \mathrm{C}$ & 0.846 & 0.738 \\
\hline $35.9{ }^{\circ} \mathrm{C}$ & 0.769 & 0.717 \\
\hline $35.9{ }^{\circ} \mathrm{C}$ & 0.769 & 0.704 \\
\hline $36.1{ }^{\circ} \mathrm{C}$ & 0.692 & 0.674 \\
\hline $36.2{ }^{\circ} \mathrm{C}$ & 0.692 & 0.648 \\
\hline $36.3^{\circ} \mathrm{C}$ & 0.692 & 0.590 \\
\hline $36.4^{\circ} \mathrm{C}$ & 0.692 & 0.531 \\
\hline $36.5^{\circ} \mathrm{C}$ & 0.692 & 0.435 \\
\hline $36.6{ }^{\circ} \mathrm{C}$ & 0.615 & 0.332 \\
\hline $36.7{ }^{\circ} \mathrm{C}$ & 0.615 & 0.231 \\
\hline $36.8^{\circ} \mathrm{C}$ & 0.538 & 0.130 \\
\hline $36.9^{\circ} \mathrm{C}$ & 0.538 & 0.085 \\
\hline $36.9^{\circ} \mathrm{C}$ & 0.462 & 0.062 \\
\hline $37.1{ }^{\circ} \mathrm{C}$ & 0.462 & 0.041 \\
\hline $37.2{ }^{\circ} \mathrm{C}$ & 0.462 & 0.033 \\
\hline $37.3{ }^{\circ} \mathrm{C}$ & 0.462 & 0.028 \\
\hline $37.4{ }^{\circ} \mathrm{C}$ & 0.462 & 0.018 \\
\hline $37.5^{\circ} \mathrm{C}$ & 0.462 & 0.013 \\
\hline $37.6{ }^{\circ} \mathrm{C}$ & 0.077 & 0.008 \\
\hline $37.7^{\circ} \mathrm{C}$ & 0 & 0.008 \\
\hline $37.8^{\circ} \mathrm{C}$ & 0 & 0.007 \\
\hline $37.9{ }^{\circ} \mathrm{C}$ & 0 & 0.005 \\
\hline $39.0^{\circ} \mathrm{C}$ & 0 & 0 \\
\hline
\end{tabular}

